\title{
Reduced administration of rasburicase for tumor lysis syndrome: A single-institution experience
}

\author{
MIHOKO TAKAI $^{1}$, TAKAHIRO YAMAUCHI ${ }^{1}$, YASUFUMI MATSUDA $^{1}$, KATSUNORI TAI $^{1}$, \\ SATOSHI IKEGAYA $^{2}$, SHINJI KISHI ${ }^{1}$, YOSHIMASA URASAKI ${ }^{1}$, AKIRA YOSHIDA ${ }^{1}$, \\ HIROMICHI IWASAKI ${ }^{2}$ and TAKANORI UEDA ${ }^{1}$ \\ ${ }^{1}$ Department of Hematology and Oncology; ${ }^{2}$ Division of Infection Control, Faculty of Medical Sciences, University of Fukui, \\ Eiheiji, Fukui 910-1193, Japan
}

Received May 8, 2014; Accepted January 29, 2015

DOI: $10.3892 / \mathrm{ol} .2015 .3009$

\begin{abstract}
In the present study, the dosage and duration of rasburicase administration were retrospectively evaluated for the ability to control the serum uric acid (S-UA) level in 13 patients diagnosed with hematological malignancies and tumor lysis syndrome (TLS), or those at risk of developing TLS, at the University of Fukui Hospital. At the time of diagnosis, seven patients already exhibited laboratory TLS, and three demonstrated clinical TLS. All patients received rasburicase in addition to chemotherapy agents. The median dose was $0.19 \mathrm{mg} / \mathrm{kg}$ (range, $0.13-0.25 \mathrm{mg} / \mathrm{kg}$ ), and the median duration was four days (range, 1-7 days). Six patients sequentially received a xanthine oxidase inhibitor, allopurinol or febuxostat. The primary estimate was the normalization of the S-UA level at the end of rasburicase treatment and on treatment day seven. The average S-UA level prior to treatment was $10.4 \pm 4.5 \mathrm{mg} / \mathrm{dl}$ (mean 土standard deviation), and 11 out of 13 patients demonstrated a S-UA level $>7 \mathrm{mg} / \mathrm{dl}$. The S-UA level at the end of rasburicase administration was $0.5 \pm 1.5 \mathrm{mg} / \mathrm{dl}$ and the S-UA level at day seven was $1.4 \pm 1.5 \mathrm{mg} / \mathrm{dl}$. All the patients achieved normalization of the S-UA level. On day seven subsequent to the initiation of treatment, the patients receiving rasburicase for a maximum of three days exhibited an S-UA level of $1.9 \pm 1.8 \mathrm{mg} / \mathrm{dl}$, while the patients receiving rasburicase for longer than three days demonstrated an S-UA level of 1.0 $\pm 1.3 \mathrm{mg} / \mathrm{dl}$ ( $\mathrm{P}=0.20$; Mann-Whitney test). The administration of $0.13 \mathrm{mg} / \mathrm{kg}$ and $0.22 \mathrm{mg} / \mathrm{kg}$ resulted in comparable UA level reductions. The administration of allopurinol or febuxostat following rasburicase administration suppressed the re-increase in S-UA level. Therefore, it was
\end{abstract}

Correspondence to: Dr Takahiro Yamauchi, Department of Hematology and Oncology, Faculty of Medical Sciences, University of Fukui, 23-3 Shimoaizuki, Matsuoka, Eiheiji, Fukui 910-1193, Japan

E-mail: tyamauch@u-fukui.ac.jp

Abbreviations: TLS, tumor lysis syndrome; S-UA, serum uric acid

Key words: tumor lysis syndrome, rasburicase, hematological malignancy, hyperuricemia concluded that reduced administration of rasburicase successfully controlled the S-UA level in TLS.

\section{Introduction}

Tumor lysis syndrome (TLS) is a life-threatening oncological emergency that is caused by the abrupt and massive lysis of cancer cells (1-6). The cell lysis leads to the rapid release of intracellular metabolites, including nucleic acids, proteins, phosphorus and potassium. This process can potentially cause hyperuricemia, hyperkalemia, hyperphosphatemia and hypocalcemia, thereby inducing renal insufficiency, cardiac arrhythmias, seizures and neurological disorders, ultimately resulting in mortality (1-6). However, TLS is preventable at an early stage, and it is essential to identify patients at risk of TLS and those requiring TLS management $(2,3)$.

An international TLS expert consensus panel developed guidelines for a medical decision tree to assign the classifications of a low, intermediate and high risk of TLS to patients with cancer $(2,3)$. Patients are assigned to low-, intermediate- and high-risk groups based on the type of malignancy, white blood cell count, lactate dehydrogenase level, type of therapy, presence of renal damage, and levels of uric acid (UA), phosphate and potassium. This risk stratification enables the appropriate management of each group $(2,3)$.

The management of TLS includes aggressive hydration and a reduction in the serum UA (S-UA) level through the administration of drugs that decrease the production of UA or degrade UA $(2,3,5,6)$. Hyperuricemia results from the rapid catabolism of purine-containing nucleic acids from cancer cells, since purine nucleotides are converted to hypoxanthine, xanthine, and finally to UA by xanthine oxidase (6). In the aforementioned guidelines, two UA-decreasing agents, the conventional xanthine oxidase inhibitor allopurinol and the recombinant uricase rasburicase are recommended to be employed in the management of TLS. Allopurinol is used to treat patients at an intermediate risk of TLS and the rasburicase is used in patients with a high risk $(2,3)$.

Rasburicase (Japan, Rasritek ${ }^{\mathrm{TM}}$; Europe, Fasturtec ${ }^{\mathrm{TM}}$; USA, Elitek ${ }^{\mathrm{TM}}$; Sanofi, Paris, France) is a recombinant form of an Aspergillus-derived urate oxidase that is expressed in a Saccharomyces cerevisiae vector (6-10). Urate oxidase, which 
is not present in humans, metabolizes UA to the more soluble allantoin, carbon dioxide and hydrogen peroxide. Allantoin is readily excreted by the kidneys. The UA-lowering efficacy of rasburicase is prompt and potent, and the administration of rasburicase appears to be extremely well tolerated (6-10). The approved method of administration in Japan is $0.2 \mathrm{mg} / \mathrm{kg}$ once daily, as an intravenous infusion administered over a 30-min period, for a maximum of seven days (11). Nevertheless, smaller doses and a shorter duration of administration of rasburicase are suggested to be equally efficacious $(12,13)$. Therefore, the optimal dosing and duration of rasburicase have not yet been established.

The present retrospective study investigated the efficacy of rasburicase in patients with hematological malignancies accompanied by TLS and those at risk of TLS at the University of Fukui Hospital. A xanthine oxidase inhibitor, either allopurinol or febuxostat, was used in combination with rasburicase in certain cases. The UA-lowering efficacy was assessed by the dosage and the duration of rasburicase, which differed according to the physicians' decision. In addition, the economics of the reduced use of rasburicase treatment was evaluated in the present study, due to the expense of the agent.

\section{Patients and methods}

Patients. Patients that were admitted to the University of Fukui Hospital between March 2011 and February 2013 were retrospectively evaluated in the present study. The study was approved by the ethics committee of University of Fukui Hospital, (Fukui, Japan). All patients had been diagnosed with hematological malignancies and already exhibited TLS or were at risk of TLS. These patients received rasburicase for the indicated durations, with or without the sequential administration of a xanthine oxidase inhibitor, either febuxostat or allopurinol, during induction chemotherapy. The patients did not receive any other medications that may have affected the S-UA level, which included losartan, fenofibrate, atorvastatin, pyrazinamide and cyclosporine.

Classification of TLS. The risk classification for TLS was made based on previously reported guidelines (2). Diseases at an intermediate risk for TLS consisted of acute myeloid leukemia with a peripheral white blood cell count between $1 \times 10^{4}$ and $5 \times 10^{4}$ cells/ $\mu 1$, acute lymphoblastic leukemia with a peripheral white blood cell count between $5 \times 10^{4}$ and $1 \times 10^{5}$ cells $/ \mu 1$, diffuse large B cell non-Hodgkin's lymphoma, and other hematological malignancies that would proliferate rapidly with expected rapid response to therapy (2). Diseases at a high risk included acute monoblastic leukemia, acute myeloid leukemia with a peripheral white blood cell count $\geq 5 \times 10^{4}$ cells $/ \mu 1$, and acute lymphoblastic leukemia with a peripheral white blood cell count $\geq 1 \times 10^{5}$ cells $/ \mu$ l (2). TLS is divided into laboratory TLS and clinical TLS. Laboratory TLS is defined according to abnormal serum values of UA, potassium, phosphate or calcium $(1,2)$. Clinical TLS requires the presence of clinical manifestations, including increased creatinine levels, cardiac arrhythmia and seizure, in addition to laboratory TLS. The treatment algorithm was based on the aforementioned guidelines (2).
Categorizing the type of hyperuricemia. Hyperuricemia is broadly classified into UA-overproduction,UA-under-excretion and combined types, according to the guidelines for the management of hyperuricemia and gout that were published in Japan in 2010 (14). The urinary UA excretion, UA clearance and creatinine clearance rates were determined for the categorization of hyperuricemia. A urinary UA excretion rate of $>0.51 \mathrm{mg} / \mathrm{kg} / \mathrm{h}$ and a UA clearance rate of $>7.3 \mathrm{ml} / \mathrm{min}$ was defined as overproduction type, a urinary UA excretion rate of $<0.48 \mathrm{mg} / \mathrm{kg} / \mathrm{h}$ or a UA clearance rate of $<7.3 \mathrm{ml} / \mathrm{min}$ was classified as under-excretion type, and a UA excretion rate of $>0.51 \mathrm{mg} / \mathrm{kg} / \mathrm{h}$ and a UA clearance rate of $<7.3 \mathrm{ml} / \mathrm{min}$ was classified as combined type.

Treatments and assessments. All patients received rasburicase. The standard method of administration of rasburicase is $0.2 \mathrm{mg} / \mathrm{kg} /$ day for a maximum of seven days, which is covered by the national health insurance system in Japan. In the patients analyzed in the present study, the use of rasburicase was modified depending on the level of S-UA, according to the physicians' decision. Induction chemotherapy was initiated with a regimen suitable for each patient, alongside the administration of rasburicase. In certain cases, xanthine oxidase inhibitors, such as allopurol or febuxostat, were used in combination with the other agents. The primary endpoint was the normalization of the S-UA level to $\leq 7 \mathrm{mg} / \mathrm{dl}$ at the end of rasburicase treatment and on the seventh day subsequent to the first administration of rasburicase. The S-UA levels were determined at the University of Fukui Hospital using a TBA-c16000 automatic analyzer (Toshiba, Otawara, Tochigi, Japan) (15).

Calculation of the cost of TLS treatment. The total drug cost for treating TLS was calculated for each patient. Rasburicase (Rasritek; $7.5 \mathrm{mg}$ ) is priced at 49,938 yen in Japan, according to the standard price of these drugs determined by the Ministry of Health, Labour and Welfare in Japan, 2012. Febuxostat (Feburic ${ }^{\mathrm{TM}}$ ) at weights of 10, 20 and $40 \mathrm{mg}$ costs 31.1, 56.4 and 106.6 yen, respectively. Allopurinol (Zyloric ${ }^{\mathrm{TM}}$ ) at a weight of $100 \mathrm{mg}$ is 25.3 yen. If Rasritek is used in the standard regimen of $0.2 \mathrm{mg} / \mathrm{kg} /$ day for seven days, the total cost is 699,132 yen for an ordinary adult patient $(60 \mathrm{~kg})$.

Statistical analyses. All statistical analyses were performed using Microsoft Excel 2007 software (Microsoft, Redmond, WA, USA). All graphs were generated using GraphPad Prism software (version 5.0; GraphPad Software, Inc., San Diego, CA, USA). The data are reported as the mean \pm standard deviation.

\section{Results}

Patient characteristics. A total of 13 patients admitted to the University of Fukui Hospital between March 2011 and February 2013 were evaluated retrospectively (Table I). The median age was 67 years (range, 26-89 years), with eight males and five females. The diagnoses included diffuse large B-cell lymphoma $(n=4)$, acute myeloid leukemia $(n=7)$, acute lymphoblastic leukemia $(n=1)$, and myelodysplastic syndrome $(n=1)$. Patients 1, 3 and 6 already exhibited clinical TLS, while patients 3, 5, 7-9, 11 and 12 demonstrated laboratory TLS (Table I). 


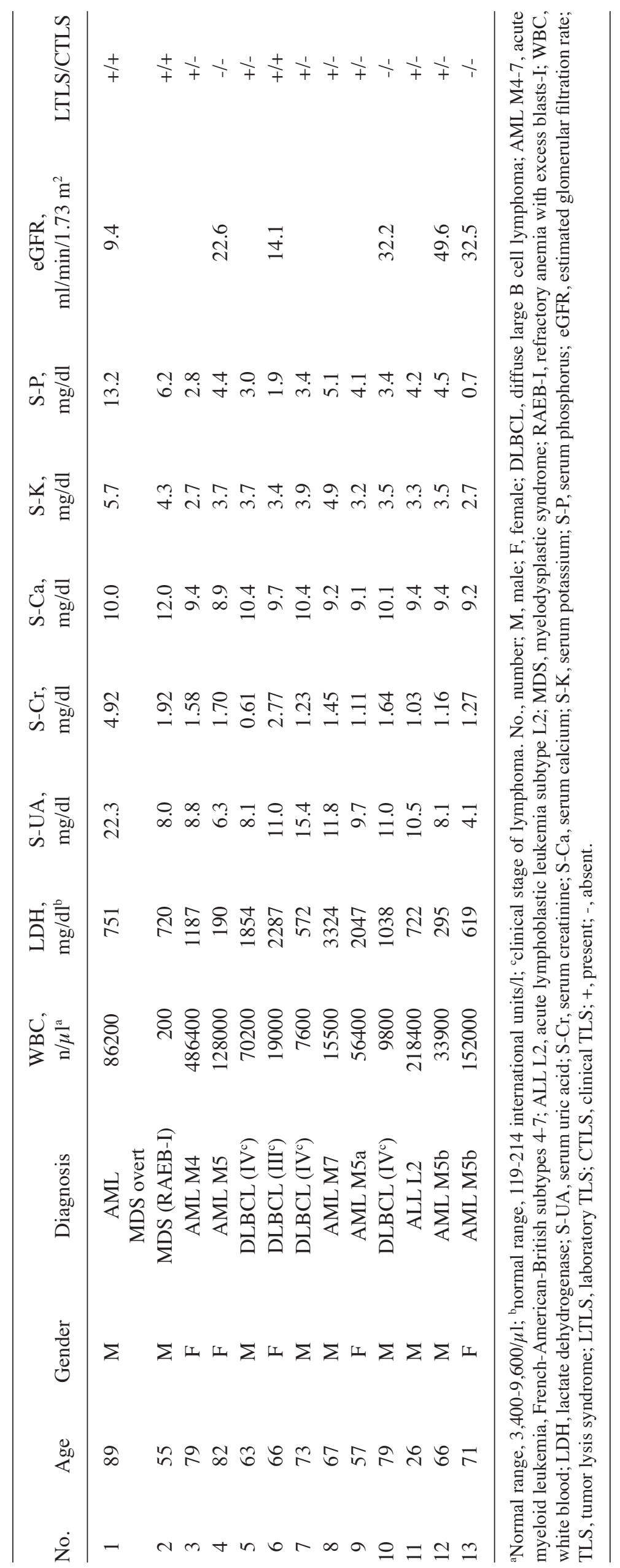




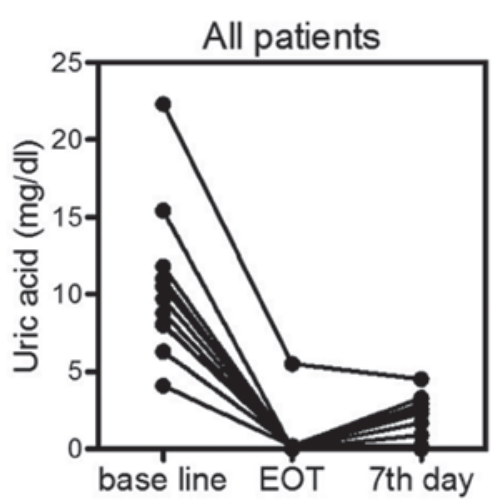

Figure 1. Time course of serum uric acid (S-UA) levels in all patients. The S-UA levels were recorded as a baseline, at the end of rasburicase administration and on the seventh day subsequent to the first dosing with rasburicase. EOT, end of rasburicase treatment.

UA-associated parameters. Eleven patients already presented hyperuricemia (patient numbers 1-3 and 5-12). The parameters associated with UA were determined in five patients (patients 1, 2, 8, 9 and 12), which included the urinary UA excretion and the UA clearance rates (Table II). On the basis of previously reported criteria (14), three cases were classified as UA overproducers and two cases were classified as UA under-excretors (Table II).

Method of administration of rasburicase. All patients underwent induction chemotherapy for the treatment of the diagnosed malignancies. Concomitantly, rasburicase was administered at various doses and durations (Table III). The median dose was $0.19 \mathrm{mg} / \mathrm{kg}$, and the median duration was four days. Seven patients received rasburicase alone (patients 1,5-8, 10 and 11), while six patients received rasburicase in combination with a xanthine oxidase inhibitor, either allopurinol (patients 2-4) or febuxostat (patients 9,12 and 13) (Table III).

UA-lowering efficacy. The primary estimate of the present retrospective study was the normalization of the S-UA level at the end of rasburicase treatment and on the seventh day subsequent to the first administration of rasburicase. While the S-UA baseline level was $10.4 \pm 4.5 \mathrm{mg} / \mathrm{dl}$, the S-UA level at the end of rasburicase administration was $0.5 \pm 1.5 \mathrm{mg} / \mathrm{dl}$ (paired $t$-test; $\mathrm{P}<0.0001)$ and the S-UA level on day seven was $1.4 \pm 1.5 \mathrm{mg} / \mathrm{dl}$ (paired $t$-test, $\mathrm{P}<0.0001$ ) (Fig. 1). All patients achieved the response criteria of normalization of the S-UA level. The patients were divided into two groups, a short-duration group, in which the patients received rasburicase for a maximum of three days, and a long-duration group, in which the patients received rasburicase for more than three days. The time course of S-UA was compared between these two groups (Fig. 2A and B). The S-UA level at baseline was $10.5 \pm 6.2 \mathrm{mg} / \mathrm{dl}$ for the short-duration group and $10.3 \pm 3.0 \mathrm{mg} / \mathrm{dl}$ for the long-duration group ( $\mathrm{P}=0.47$, Mann-Whitney test) (Fig. 2C). The S-UA level on day seven was $1.9 \pm 1.8 \mathrm{mg} / \mathrm{dl}$ for the short-duration group and $1.0 \pm 1.3 \mathrm{mg} / \mathrm{dl}$ for the long-duration group $(\mathrm{P}=0.20$, Mann-Whitney test; Fig. 2D). This suggested that the S-UA level remained in the normal range in the short-duration group, although a non-significant re-increase in the S-UA level was observed.
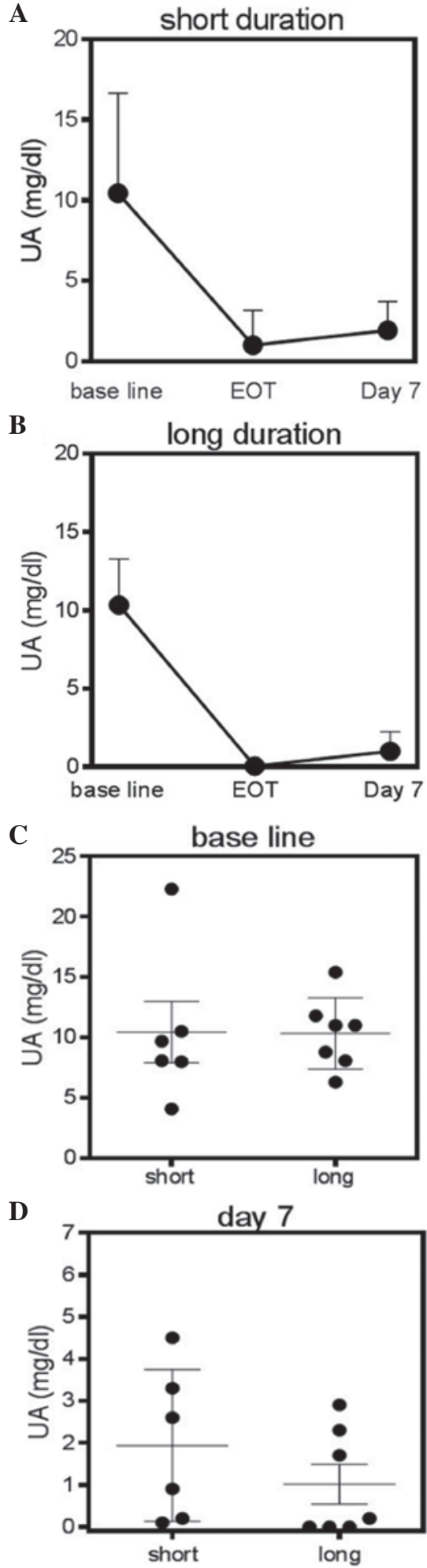

Figure 2. (A and B) Comparison of the time course of S-UA levels between the patients receiving rasburicase for a maximum of three days (short duration) and the patients receiving rasburicase for more than three days (long duration). These values represent the mean \pm standard deviation. (C and D) Comparison of the S-UA level at the baseline measurement (C) and on the seventh day subsequent to the first dosing of rasburicase (D) between the short-duration group and the long-duration group. EOT, end of rasburicase treatment; S-UA, serum uric acid.

Clinical course of the S-UA level in certain patients. Patient 10 received rasburicase treatment for seven days, and the S-UA level was completely suppressed (Fig. 3A). By 
A

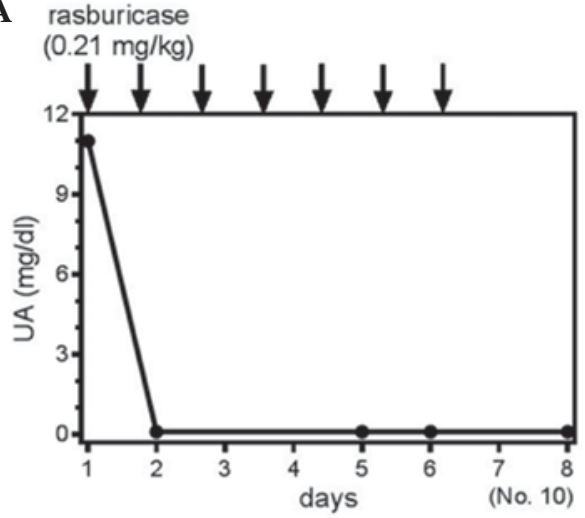

B
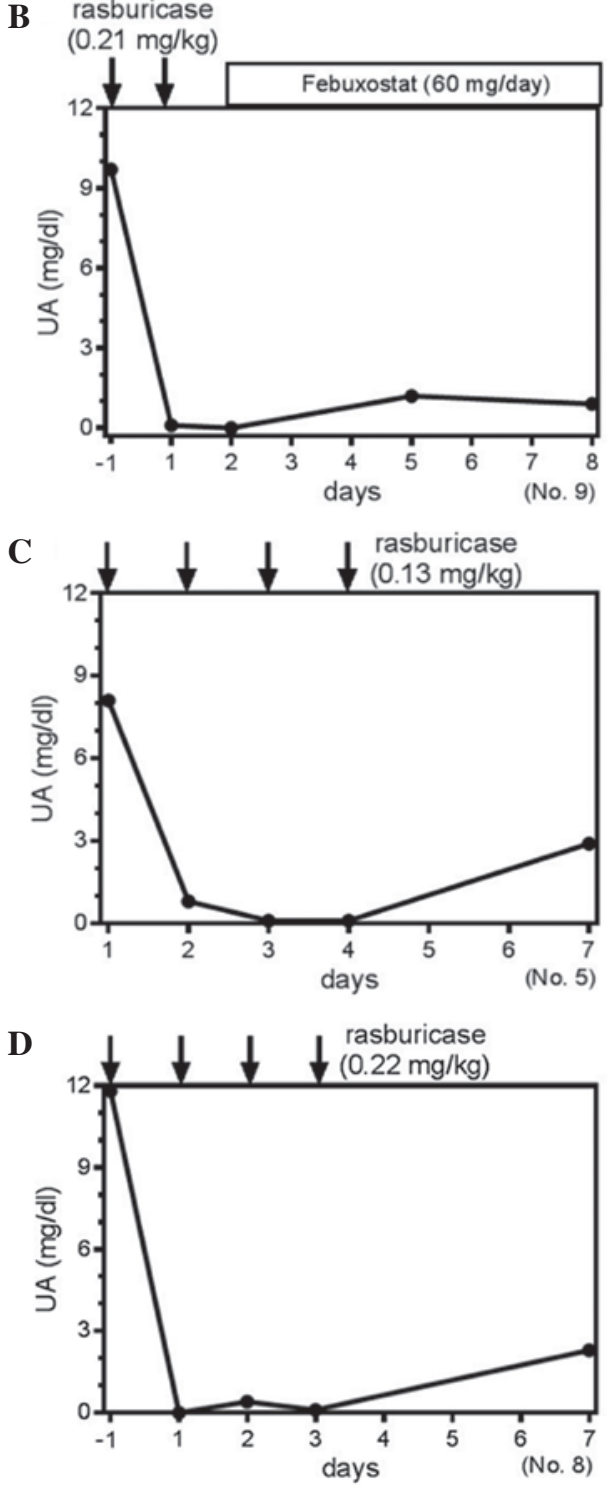

Figure 3. Time course of serum UA levels in four patients that received rasburicase for various lengths of time. (A) Patient 10 received seven days of rasburicase therapy at a dose of $0.21 \mathrm{mg} / \mathrm{kg}$. (B) Patient 9 received two days of rasburicase therapy at a dose of $0.21 \mathrm{mg} / \mathrm{kg}$, followed by the administration of febuxostat at $10 \mathrm{mg}$ daily. (C) Patient 5 received rasburicasetherapy for four days at a dose of $0.13 \mathrm{mg} / \mathrm{kg}$. (D) Patient 8 received rasburicase therapy for four days at a dose of $0.22 \mathrm{mg} / \mathrm{kg}$. UA, uric acid.

contrast, patient 9 received two days of rasburicase treatment followed by the administration of febuxostat (Fig. 3B). In this case, despite the short duration of rasburicase use, sequential
Table II. Classification of hyperuricemia.

\begin{tabular}{cccc}
\hline Patient & $\begin{array}{c}\text { U-UA, } \\
\mathrm{mg} / \mathrm{kg}^{\mathrm{a}}\end{array}$ & $\begin{array}{c}\text { C-UA, } \\
\mathrm{ml} / \mathrm{min}^{\mathrm{b}}\end{array}$ & Type of hyperuricemia \\
\hline 1 & 0.12 & 2.8 & Underexcretion \\
2 & 0.35 & 4.6 & Underexcretion \\
8 & 0.74 & 7.0 & Overproduction \\
9 & 0.51 & 5.0 & Overproduction \\
12 & 0.71 & 3.6 & Overproduction \\
\hline
\end{tabular}

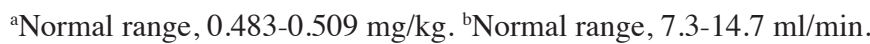
U-UA, urinary uric acid excretion; C-UA, uric acid clearance.

administration of febuxostat was suggested to suppress the S-UA level further (Fig. 3B). For the comparison between various dosages of rasburicase, patients five and eight received rasburicase for four days at the doses of $0.13 \mathrm{mg} / \mathrm{kg}$ and $0.22 \mathrm{mg} / \mathrm{kg}$, respectively (Fig. 3C and D). These two cases clearly demonstrated an equivalent time course to achieving normalized S-UA levels (Fig. 3C and D), indicating that a smaller dose was equally effective for controlling S-UA production. Thus, the administration of rasburicase at smaller doses or for a shorter period of administration may be efficacious for managing the S-UA level in patients receiving chemotherapy with TLS or at risk of developing TLS. These results suggest that the method of administration of rasburicase may continue to require optimization.

Economic considerations. The cost of drugs for treating TLS was calculated in each patient (Table II). When the cost for the standard regime of rasburicase treatment, consisting of $0.2 \mathrm{mg} / \mathrm{kg}$ /day for seven days, totaling 699,132 yen, was set as $100 \%$, the mean real drug cost for treating TLS was 326,714 yen (range, 99,876-699,132 yen), or 47\% (range, 14-100\%), in all patients. This suggests that the cost for treating TLS largely depends on the use of rasburicase, regardless of the addition of allopurinol or febuxostat.

\section{Discussion}

Hyperuricemia in TLS occurs through the catabolism of purine nucleic acid released from cancer cells upon cell lysis. It is logical to block xanthine oxidase, which converts purine metabolites such as hypoxanthine and xanthine to UA, thereby reducing the production of UA $(2,3,8)$. However, xanthine oxidase inhibitors do not reduce the already generated UA. Rasburicase effectively converts UA into much more soluble allantoin $(6,16)$ in the blood, thereby preventing the crystallization of UA that may lead to renal damage.

The present retrospective study revealed that rasburicase was used at various doses for various durations in an actual clinical setting (Table III), although the approved method of administration in Japan is $0.2 \mathrm{mg} / \mathrm{kg}$ once daily for a maximum of seven days. Nevertheless, rasburicase effectively reduced and normalized the S-UA levels during induction chemotherapy in all of the patients (Figs. 1 and 2). The re-increase in S-UA subsequent to the discontinuation of rasburicase 
Table III. Chemotherapies and uric acid-lowering therapies.

\begin{tabular}{|c|c|c|c|c|c|c|c|c|c|}
\hline \multirow[b]{2}{*}{ Patient } & \multirow[b]{2}{*}{$\begin{array}{l}\text { TLS } \\
\text { risk }\end{array}$} & \multirow[b]{2}{*}{ Chemotherapy } & \multicolumn{2}{|c|}{ Rasburicase } & \multicolumn{2}{|c|}{ Febuxostat } & \multicolumn{2}{|c|}{ Allopurinol } & \multirow[b]{2}{*}{$\begin{array}{c}\text { Cost, } \\
\%^{\mathrm{b}}\end{array}$} \\
\hline & & & $\begin{array}{l}\text { Dose, } \\
\mathrm{mg} / \mathrm{kg}\end{array}$ & $\begin{array}{c}\text { Duration, } \\
\text { days }^{\mathrm{a}}\end{array}$ & $\begin{array}{l}\text { Dose, } \\
\mathrm{mg} / \mathrm{kg}\end{array}$ & $\begin{array}{c}\text { Duration, } \\
\text { days }^{\mathrm{a}}\end{array}$ & $\begin{array}{l}\text { Dose, } \\
\mathrm{mg} / \mathrm{kg}\end{array}$ & $\begin{array}{c}\text { Duration, } \\
\text { days }^{\mathrm{a}}\end{array}$ & \\
\hline 1 & & Low-dose ara-C & 0.19 & 6 & & & & & 14 \\
\hline 2 & & Ara-C-based & 0.18 & $6-7$ & & & 200 & $1-7$ & 29 \\
\hline 3 & & Ara-C-based & 0.19 & $1-5$ & & & 200 & $1-7$ & 71 \\
\hline 4 & High & Ara-C-based & 0.19 & $1-5$ & & & 200 & $1-7$ & 36 \\
\hline 5 & & DEX & 0.13 & $1-4$ & & & & & 29 \\
\hline 6 & & RCHOP & 0.14 & $1-7$ & & & & & 50 \\
\hline 7 & & RCHOP & 0.18 & $-1-5$ & & & & & 86 \\
\hline 8 & & Ara-C-based & 0.23 & $-1-3$ & & & & & 57 \\
\hline 9 & & Ara-C-based & 0.21 & $-1-1$ & 60 & $2-6$ & & & 29 \\
\hline 10 & Int & RCHOP-like & 0.21 & $1-7$ & & & & & 100 \\
\hline 11 & & $\mathrm{CPA}+\mathrm{DNR}+\mathrm{PSL}$ & 0.25 & $1,6,7$ & & & & & 43 \\
\hline 12 & & Ara-C-based & 0.19 & $1-3$ & 10 & $-7-7$ & & & 43 \\
\hline 13 & High & Ara-C-based & 0.17 & $1-3$ & 10 & $-1-7$ & & & 21 \\
\hline
\end{tabular}

The patients were treated with rasburicase, with or without the xanthine oxidase inhibitors allopurinol or febuxostat. ${ }^{\mathrm{a}}$ The day from the initiation of chemotherapy. ${ }^{b}$ Percentage cost for each patient for treatment of TLS relative to the cost of the standard use of rasburicase $(0.2 \mathrm{mg} / \mathrm{kg} / \mathrm{day}$, seven days). TLS, tumor lysis syndrome; Int, intermediate; Ara-C, cytarabine; ara-C-based, the combination of cytarabine (70-100 mg/m ${ }^{2}$ for 5-7 days) and anthracycline (idarubicin, $8-12 \mathrm{mg} / \mathrm{m}^{2}$ for 1-3 days, or daunorubicin, $30-50 \mathrm{mg} / \mathrm{m}^{2}$ for 3-5 days); DEX, dexamethasone; RCHOP, rituximab $\left(375 \mathrm{mg} / \mathrm{m}^{2}\right)$, cyclophosphamide $\left(750 \mathrm{mg} / \mathrm{m}^{2}\right)$, doxorubicin $\left(50 \mathrm{mg} / \mathrm{m}^{2}\right)$, vincristine $\left(1.4 \mathrm{mg} / \mathrm{m}^{2}\right)$ and prednisolone $(100 \mathrm{mg})$; CPA, cyclophosphamide; DNR, daunorubicin; PSL, prednisolone.

administration was further suppressed by the use of xanthine oxidase inhibitor (Fig. 3). In addition, the reduction in the dose of rasburicase did not appear to attenuate the UA-reducing activity (Fig. 3).

Ishizawa et al prospectively compared the administration of two different doses of rasburicase, $0.15 \mathrm{mg} / \mathrm{kg}$ and $0.2 \mathrm{mg} / \mathrm{kg}$, in Japanese adult patients with leukemia or lymphoma (17). The primary endpoint was the normalization of the S-UA level from $48 \mathrm{~h}$ subsequent to the first infusion to $24 \mathrm{~h}$ subsequent to the last infusion. The overall response rate was $100.0 \%$ with the administration of $0.15 \mathrm{mg} / \mathrm{kg}$ rasburicase and $96.0 \%$ with $0.20 \mathrm{mg} / \mathrm{kg}$ rasburicase, indicating that the two dose levels were equally effective for controlling the S-UA level. McBride et al evaluated single fixed dosing versus weight-based dosing strategies for rasburicase to determine the minimum dose required to mitigate hyperuricemia in the treatment or prevention of TLS in a total of 373 patients with a hematological malignancy or solid tumor (18). The patients were divided into groups receiving 3,6 or $7.5 \mathrm{mg}$ rasburicase, or those receiving weight-based dosing. The primary endpoint was a S-UA level $<7.5 \mathrm{mg} / \mathrm{dl}$ obtained within $24 \mathrm{~h}$ of receiving rasburicase. McBride et al found that all the treatments provided comparable UA-lowering efficacy, but the $6 \mathrm{mg}$ dose resulted in lower sustained UA levels than the $3 \mathrm{mg}$ dose (18). Vadhan-Raj et al compared the UA-lowering efficacy of rasburicase $(0.15 \mathrm{mg} / \mathrm{kg})$ administered as a single dose and daily dosing for five days in adult patients at risk for TLS prospectively (19). The primary endpoint was the normalization of the S-UA level within $48 \mathrm{~h}$ and the persistence of normal S-UA for five days. In total, 39 out of 40 (98\%) patients in the daily-dose arm and 34 out of $40(85 \%)$ patients in the single-dose arm demonstrated a sustained S-UA response, although six patients within the single-dose arm required a second dose for S-UA levels $>7.5 \mathrm{mg} / \mathrm{dl}$ (19). Cortes et al (20) compared the UA-lowering efficacy between rasburicase at a dose of $0.2 \mathrm{mg} / \mathrm{kg}$ (days 1-5), rasburicase plus allopurinol at a rasburicase dose of $0.2 \mathrm{mg} / \mathrm{kg}$ (days 1-3) and an allopurinol dose of $300 \mathrm{mg}$ (days 3-5), and allopurinol at a dose of $300 \mathrm{mg}$ (days 1-5) for patients at risk of TLS, using a prospective study design (20). The UA response rate was defined as the percentage of patients achieving or maintaining S-UA $\leq 7.5 \mathrm{mg} / \mathrm{dl}$ during days $3-7$. The response rates were $87 \%$ for rasburicase alone, $78 \%$ for rasburicase plus allopurinol, and $66 \%$ for allopurinol alone (20). These studies suggested that a reduced dose or shorter duration of rasburicase administration effectively controlled the S-UA level in the majority of cases, but a re-increase in S-UA may require additional dosing or sequential use of allopurinol.

In the present retrospective study, rasburicase was not administered in a uniform regimen. Nevertheless, a reduced dose or shorter duration of rasburicase administration was efficacious for managing S-UA in patients with hematological malignancies and TLS or those at risk of developing TLS. The combination of rasburicase and febuxostat demonstrated a rapid decrease in S-UA level and suppressed the re-increase (Fig. 3), suggesting that such a combination would be a mechanistically more reasonable and cost-effective approach that treatment with rasburicase alone (Table III). The present study did not reveal the most appropriate dose and schedule for rasburicase administration. However, careful monitoring of S-UA levels 
may individualize rasburicase therapy for each patient through adjustment of the dose and the duration, and by combination with a xanthine oxidase inhibitor.

\section{References}

1. Cairo MS and Bishop M: Tumour lysis syndrome: new therapeutic strategies and classification. Br J Haematol 127: 3-11, 2004.

2. Coiffier B, Altman A, Pui CH, Younes A and Cairo MS: Guidelines for the management of pediatric and adult tumor lysis syndrome: an evidence-based review. J Clin Oncol 26: 2767-2778, 2008.

3. Cairo MS, Coiffier B, Reiter A and Younes A; TLS expert panel: Recommendations for the evaluation of risk and prophylaxis of tumour lysis syndrome (TLS) in adults and children with malignant diseases: an expert TLS panel consensus. $\mathrm{Br}$ J Haematol 149: 578-586, 2010.

4. Howard SC, Jones DP and Pui CH: The tumor lysis syndrome. N Engl J Med 364: 1844-1854, 2011.

5. Firwana BM, Hasan R, Hasan N, Alahdab F, Alnahhas I, Hasan S and Varon J: Tumor lysis syndrome: a systematic review of case series and case reports. Postgrad Med 124: 92-101, 2012.

6. Wilson FP and Berns JS: Onco-nephrology: tumor lysis syndrome. Clin J Am Soc Nephrol 7: 1730-1739, 2012.

7. Pui CH, Mahmoud HH, Wiley JM, Woods GM, Leverger G, Camitta B, Hastings C, Blaney SM, Relling MV and Reaman GH: Recombinant urate oxidase for the prophylaxis or treatment of hyperuricemia in patients with leukemia or lymphoma. J Clin Oncol 19: 697-704, 2001.

8. McDonnel AM, Lenz KL, Frei-Lahr DA, Hayslip J and Hall PD: Single-dose rasburicase $6 \mathrm{mg}$ in the management of tumor lysis syndrome in adults. Pharmacotherapy 26: 806-812, 2006.

9. Cammalleri L and Malaguarnera M: Rasburicase represents a new tool for hyperuricemia in tumor lysis syndrome and in gout. Int J Med Sci 4: 83-93, 2007.

10. Cheuk DK, Chiang AK, Chan GC and Ha SY: Urate oxidase for the prevention and treatment of tumor lysis syndrome in children with cancer. Cochrane Database Syst Rev 16: CD006945, 2010.

11. Ishizawa K, Ogura M, Hamaguchi M Hotta T, Ohnishi K, Sasaki T, Sakamaki H, Yokoyama H, Harigae H and Morishima Y: Safety and efficacy of rasburicase (SR29142) in a Japanese phase II study. Cancer Sci 100: 357-62, 2009.
12. Trifilio S, Gordon L, Singhal S, Tallman M, Evens A, Rashid K, Fishman M, Masino K, Pi J and Mehta J: Reduced-dose rasburicase (recombinant xanthine oxidase) in adult cancer patients with hyperuricemia. Bone Marrow Transplant 37: 997-1001, 2006.

13. Jeha S, Kantarjian H, Irwin D, Shen V, Shenoy S, Blaney S, Camitta B and Pui CH: Efficacy and safety of rasburicase, a recombinant urate oxidase (Elitek), in the management of malignancy associated hyperuricemia in pediatric and adult patients: Final results of a multicenter compassionate use trial. Leukemia 19: 34-38, 2005.

14. The guideline revising committee of Japanese Society of Gout and Nucleic Acid Metabolism. Digest of the guideline for management of hyperuricemia and gout. 2nd edition. Gout Nucleic Acid Metabol 34: 107-143, 2010 (In Japanese).

15. Yamauchi T, Negoro E, Lee S, Takai M, Matsuda Y, Takagi K, Kishi S, Tai K, Hosono N, Tasaki T, Ikegaya S, Inai K, Yoshida A, Urasaki Y, Iwasaki H and Ueda T: A high serum uric acid level is associated with poor prognosis in patients with acute myeloid leukemia. Anticancer Res 33: 3947-3951, 2013.

16. Yeldandi AV, Yeldandi V, Kumar S, Murthy CV, Wang XD, Alvares K, Rao MS and Reddy JK: Molecular evolution of the urate oxidase-encoding gene in hominoid primates: Nonsense mutations. Gene 109: 281-284, 1991.

17. Ishizawa K, Ogura M, Hamaguchi M, Hotta T, Ohnishi K, Sasaki T, Sakamaki H, Yokoyama H, Harigae $H$ and Morishima Y: Safety and efficacy of rasburicase (SR29142) in a Japanese phase II study. Cancer Sci 100: 357-362, 2009.

18. McBride A, Lathon SC, Boehmer L, Augustin KM, Butler SK and Westervelt P: Comparative evaluation of single fixed dosing and weight-based dosing of rasburicase for tumor lysis syndrome. Pharmacotherapy 33: 295-303, 2013.

19. Vadhan-Raj S, Fayad LE, Fanale MA, Pro B, Rodriguez A, Hagemeister FB, Bueso-Ramos CE, Zhou X, McLaughlin PW, Fowler N, Shah J, Orlowski RZ, Samaniego F, Wang M, Cortes JE, Younes A, Kwak LW, Sarlis NJ and Romaguera JE: A randomized trial of a single-dose rasburicase versus five-daily doses in patients at risk for tumor lysis syndrome. Ann Oncol 23: 1640-1645, 2012.

20. Cortes J, Moore JO, Maziarz RT, Wetzler M, Craig M, Matous J, Luger S, Dey BR, Schiller GJ, Pham D, Abboud CN, Krishnamurthy M, Brown A Jr, Laadem A and Seiter K: Control of plasma uric acid in adults at risk for tumor Lysis syndrome: efficacy and safety of rasburicase alone and rasburicase followed by allopurinol compared with allopurinol alone - results of a multicenter phase III study. J Clin Oncol 28: 4207-4213, 2010. 